\title{
Transformed follicular lymphoma
}

\author{
Thais Fischer $^{1} \cdot$ Natalia Pin Chuen Zing ${ }^{1}$ - Carlos Sergio Chiattone ${ }^{2}$. \\ Massimo Federico $^{3} \cdot$ Stefano Luminari $^{3,4}$
}

Received: 3 January 2017 / Accepted: 5 October 2017

(C) Springer-Verlag GmbH Germany 2017

\begin{abstract}
Follicular Lymphoma (FL) is the second most common type of non-Hodgkin lymphoma and is considered to be the prototype of indolent lymphomas. Histologic transformation into an aggressive lymphoma, which is expected to occur at a rate of 2 to $3 \%$ each year, is associated with rapid progression, treatment resistance, and poor prognosis. Recent modifications to the physiopathologic mechanism of transformed follicular lymphoma ( $t-F L)$ have been proposed, including genetic and epigenetic mechanisms as well as a role for the microenvironment. Although t-FL is considered a devastating complication, as it is associated with treatment-refractory disease and a dismal outcome, recent data in the rituximab era have suggested that not only is the prognosis less severe than reported in the previous literature but the risk of transformation is also lower. Thus, this study aimed to review the most recent research on t-FL in an attempt to better understand the clinical meaning of transformation from FL to diffuse large B cell lymphoma (DLBCL) and the impact of current treatment strategies on the curability of this intriguing subentity of lymphoma.
\end{abstract}

Stefano Luminari

stefano.luminari@asmn.re.it

1 Irmandade Santa Casa de Misericórdia de São Paulo, São Paulo, SP, Brazil

2 Santa Casa de Sao Paulo School of Medical Sciences, São Paulo, SP, Brazil

3 University of Modena and Reggio Emilia, Modena, Italy

4 Hematology Unit, Azienda Unità Sanitaria Locale IRCCS, Arcispedale Santa Maria Nuova IRCCS, viale Risorgimento $n^{\circ} 80$ 42123, Reggio Emilia, Italy
Keywords Lymphoma · Lymphoma, follicular · Lymphoma, non-Hodgkin · Lymphoma, large B cell · Diffuse · Diffuse large cell lymphoma · Epigenetic $\cdot$ Prognosis, cell neoplastic transformation $\cdot$ Cell transformation, neoplastic $\cdot$ Genetic transformation

\section{Introduction}

Follicular Lymphoma (FL) is the second most common type of non-Hodgkin lymphoma (NHL) in the USA and Europe (10$20 \%$ of NHL), with approximately 15,000 newly diagnosed cases per year [1, 2]. It is considered the prototype of indolent lymphomas, has an equal distribution between men and women, and has a median age of 65 years at presentation [3-5]. These patients are frequently diagnosed at an advanced stage, and bone marrow (BM) involvement is present in approximately $50 \%$ of the cases. Translocation $\mathrm{t}(14 ; 18)(\mathrm{q} 32 ; \mathrm{q} 21)$ places the antiapoptotic BCL-2 oncogene under the control of the immunoglobulin (Ig) heavy-chain enhancer and is a genetic hallmark of FL. The presence of this translocation has been used recently to support diagnosis and to monitor response to therapy [3, 6-12].

The occurrence of relapse characterizes the natural history of FL, which has a shorter duration of remission at every recurrence. Although major improvements have been achieved with therapy, this type of lymphoma is still considered an incurable disease. Recently, however, the natural history of the disease has been measured in decades, and a high proportion of FL patients will die due to reasons other than lymphoma progression $[3,4,13,14]$.

In spite of the improvement in the diagnostic accuracy and the efficacy of chemoimmunotherapy regimens, progression and transformation still occur [15]. The 3-year progression-free survival rate after chemoimmunotherapy is approximately 
$50 \%$, and the rate of transformation to more aggressive forms of lymphoma is $2-3 \%$ per year [8, 16-23]. The most common histologic subtype during transformation is diffuse large $\mathrm{B}$ cell lymphoma (DLBCL), but other histological subtypes may be seen such as Burkitt lymphoma (BL), lymphoblastic lymphoma, acute lymphoblastic leukemia, and occasionally, cases of Hodgkin lymphoma [14, 15, 19, 24, 25].

It is important to emphasize that t-FL implies the existence of a clonal relationship between the original FL and the subsequent aggressive subtype [15]. It has been postulated that the presence of the same immunoglobulin, immunoglobulin segments, and common somatic mutations might contribute to this relationship. In addition, other authors have suggested the existence of a common progenitor cell (CPC) that may be responsible for lymphoma persistence, resistance, recurrence, and transformation [20, 26-28].

Although histologic transformation (HT) was first described more than 65 years ago by Gall and Mallory, the biological and clinical events that characterize transformation remain incompletely understood, and many questions remain unanswered [29]. Therefore, the objective of this review is to focus on aspects of transformation to clarify the physiopathology, diagnosis, prognostic factors, and treatment. This effort aims to offer a better understanding of HT in FL, and consequently, to improve the chances of treatment effectiveness.

\section{Physiopathology of the transformation process}

To better understand the biology of the transformation process, it is important to rely on the transformation concept. Therefore, HT refers to the evolution of a clinically indolent NHL (i.e., FL) into a clinically aggressive lymphoma (i.e., DLBCL, Burkitt lymphoma, gray zone lymphoma or lymphoblastic lymphoma, and other high-grade B cell lymphomas). In addition to FL, transformation can also occur in other subtypes of indolent lymphoma, such as marginal zone lymphoma, lymphoplasmacytic lymphoma, small lymphocytic lymphoma/chronic lymphocytic leukemia, and lymphocyte predominant Hodgkin lymphoma [14, 30].

Another important concept is that transformation is not frequently a "linear" process that involves the subsequent accumulation of oncogenic mutations. In contrast, a "nonlinear" transformation, which begins with an immature precursor, seems to be the rule rather than the exception [11] (Fig. 1). Despite the existence of these two mechanisms, they are not mutually exclusive and may be independently activated in the same patient or even in the same lymph node [31] (Fig. 2). Genetic alterations that are shared between FL and t-FL are evidence of this clonal relationship [18, 31].

Previous studies have already demonstrated that t-FL most commonly arises from immature CPCs and that these cells may remain in $\mathrm{BM}$ niches during treatment, where they acquire new genomic lesions [32-34]. Even though the existence of CPCs has not been physically demonstrated, it can be postulated, and the genetic lesions that are shared between FL and t-FL may help in the understanding of the sequence of events [18]. This theory of cancer-initiating cells has been previously described in epithelial cell cancers and is associated with the cell's ability to self-renew, proliferate, and gain resistance to chemical or physical insults [31, 32].

Recent genetic studies have contributed to the expansion of the knowledge associated with transformation; however, the sequence of successive genetic hits or simultaneous alterations that produce an aggressive phenotype remains unclear [33]. The most common genetic lesions in FL and t-FL may be classified into the following cell processes (Fig. 3):

- Programmed cell death-apoptosis: $t(14 ; 18)$ translocation places the antiapoptotic BCL-2 oncogene under control of the immunoglobulin (Ig) heavy-chain enhancer (IGH/ BCL-2) $[10,34]$. This is a typical genetic lesion in FL; however, this lesion alone seems to be insufficient for the induction of clinical disease, which is reinforced by its occurrence in healthy individuals [9, 35-37]. Moreover, this $t(14 ; 18)$ translocation sufficiently lengthens the lifespan of cells to permit the acquisition of secondary alterations as well as other genetic mutations [38]. Mutated BCL-2 is seen at a higher frequency in t-FL, which thus reaffirms the importance of the accumulation of secondary alterations in the genesis of lymphoma [8].

It is important to emphasize that BCL-2 translocation has been always described in FL and t-FL, and its occurrence ensures its participation in clonal precursor expansion [18].

- Histone/chromatin modification enzymes (epigenetic regulators): methyltransferases-H3K3, MLL2, EZH2, and acetytransferases-CREBBP, EP300.

Similar to BCL-2 translocation, CREBBP expression, mutation, or the occurrence of some other alteration has been described to occur at a high frequency. Each has a uniform representation and functions as a "driver" in t-FL pathology. On the contrary, MLL2 has a variable representation, given its plausible function as an "accelerator" [38]. Therefore, the presence of alterations in MLL2 gives a selective advantage to a given clone compared with other competing clones [38].

The CREBBP and MLL2 genes were described as the most commonly affected genes in clinical FL. Alterations in these genes are present at diagnosis and are never lost during progression or transformation, which also suggests that they are early acquisitions by CPCs $[18,39]$.

- Cell cycle and DNA damage response: one of the most important events in the transformation process is CDKN2A/B loss, which is associated with inactivation 


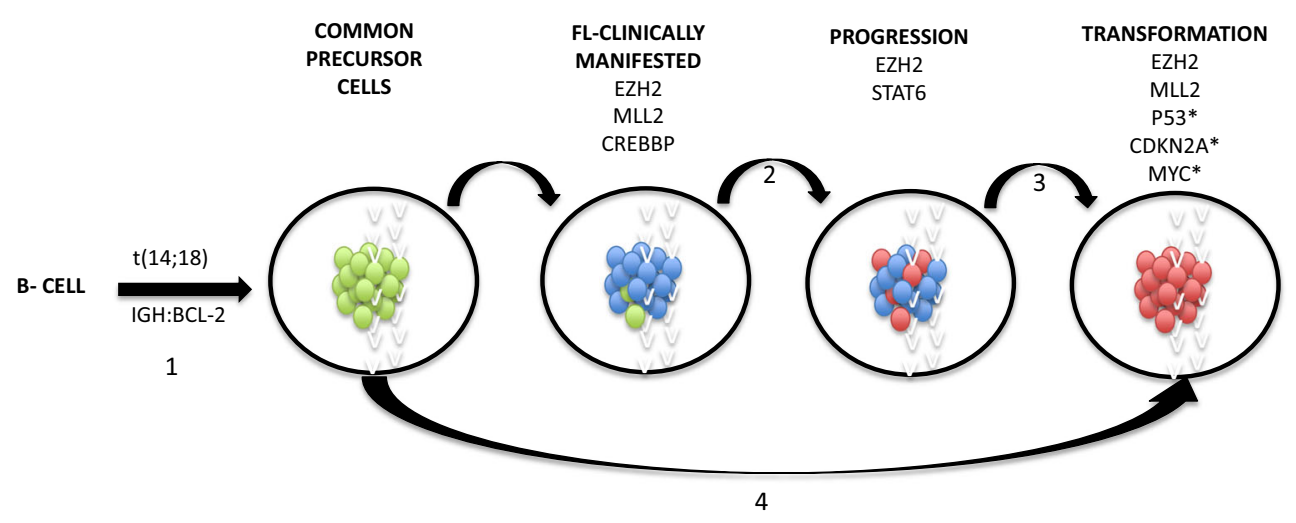

Fig. 1 Physiopathology of transformation. This simplified pathway that illustrates the driving of transformation from a B cell to a transformed follicular lymphoma (t-FL) cell. Green circles, mutated common progenitor cells (CPCs); blue circles, follicular lymphoma (FL) cells; red circles, transformed follicular lymphoma cells. 1-IGH/BCL-2 translocation is the first event in FL physiopathology, although it can

of the p53 tumor suppression gene (DNA damage response) and with expression of $\mathrm{p} 16$ protein (part of cycle cell regulation). These cause changes in G1 phase of the cell cycle and result in genomic instability $[18,40]$.

Those alterations are not typically seen in FL but are the most common aberrations in t-FL, which suggests that they are specifically acquired during transformation $[18,19]$.

- MYC aberration: MYC activation through copy number gain, amplification, deletions, or loss of heterozygosity is another important cell disruption in t-FL. It provides multiple advantages to lymphoma cells and supports cell growth, metabolism, and genetic instability $[18,41]$.

MYC aberrations are rare at diagnosis, but are frequently found at the time of progression as well as during transformation. The acquisition of MYC activation in $\mathrm{FL}$ in which BCL-2 translocation has already occurred, characterizes "double-hit" lymphoma. According to some authors, this is the second most common genetic alteration in t-FL [18, 41-43]. also occur in healthy individual cells; 2 and 3-"Linear model" of t-FL with subsequent accumulation of mutations. Some CPCs may still be present in FL samples; 4- "Nonlinear" transformation (most frequent) originates from CPCs. *P53, mutations, deletions, loss of heterozygosity/CDKN2A; deletions and or loss of heterozygosity/ MYC; translocation, amplification, or gains

In addition to that, BCL-6 translocation, which may also occur during transformation, characterizes "triplehit" lymphoma (MYC/BCL-2/BCL-6) and confers an even worse prognosis [41, 44].

It is important to emphasize that MYC alterations associated with FL might have a different origin than BL, considering that in FL, this alteration results from the cooperation between BCL-2 and the deregulation of activation-induced cytidine deaminase (AID), while in $\mathrm{BL}$, it is a consequence of $\mathrm{t}(8 ; 14)$ translocation [45].

- Other lesions (non-phase-specific lesions):

The following alterations have heterogeneous contributions to lymphoma transformation but are still the focus of some studies [18]: (a) TNFRSF14 [14, 18], member of TNF receptor superfamily, which functions in $\mathrm{T}$ cell signaling and is disrupted in $56.4 \%$ of $\mathrm{t}-\mathrm{FL}$ cases; (b) STAT6 [18], DNA-binding transcription factor implicated in IL4- and IL3-mediated responses and is mutated in $23.1 \%$ of t-FL cases; (c) CARD 11 and
Fig. 2 Follicular Lymphoma as a heterogeneous entity. a Classical FL Homogenous. b Classical FL with subpopulations (A) classical FL, (B) localized progression, (C) subpopulations in the same lymph node that may have different drivers of mutation. c Transformed FL and reminiscent areas of indolent lymphoma (D) theses reminiscent areas may be responsible for the persistence of lymphoma after different lines of therapy. $\mathbf{d}$ composite histology
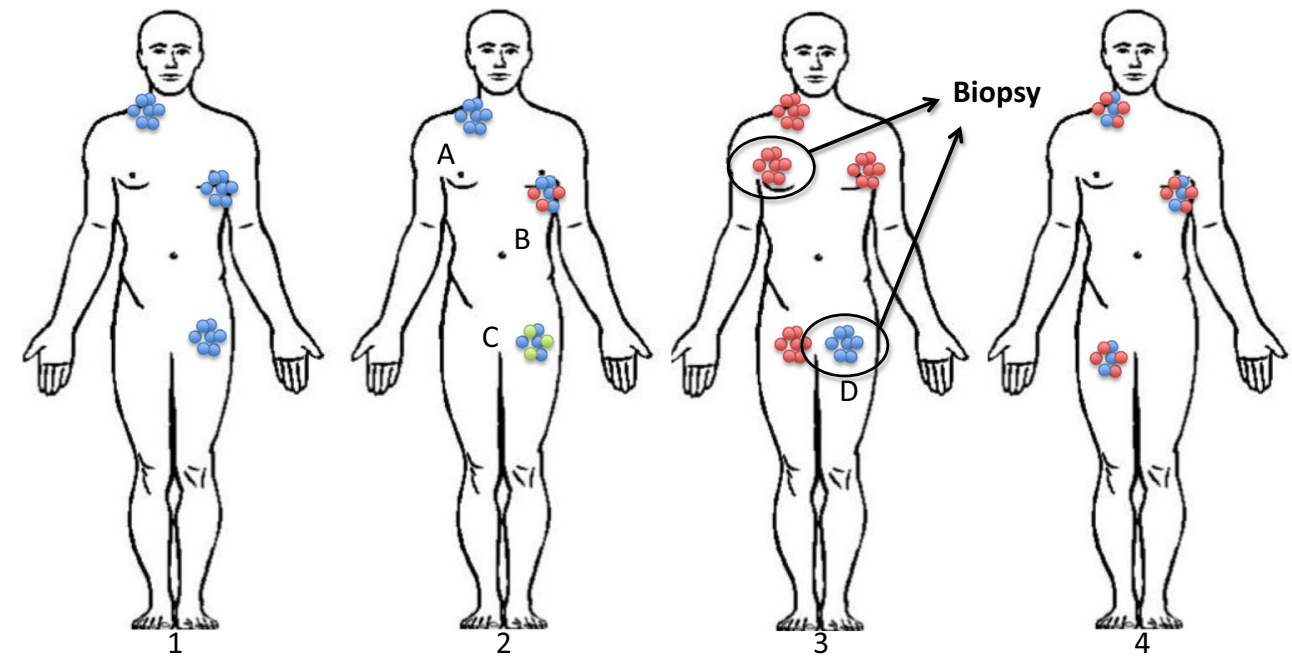


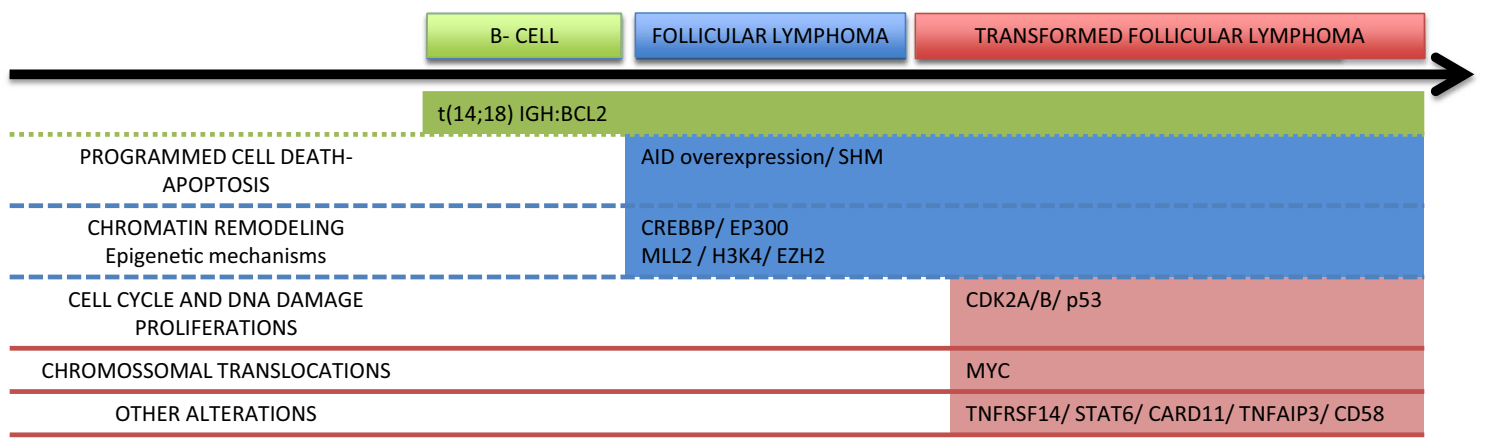

Fig. 3 The postulated tumorigenesis of t-FL. The earliest step in the development of FL is the acquisition of the IGH/BCL-2 translocation, although alone, it is insufficient to produce FL as this alteration can also be seen in the normal population. The subsequent oncogenic mutation that produced FL is thought to be related to the mistargeted activity of

CD79B [18], alters signaling pathway responses involved in the engagement of BCR and CXCR4 and is present in $10.3 \%$ of the t-FL cases; TNFAIP3 [18], regulator of $\mathrm{NFkB}$, lost in $15 \%$ of t-FL cases; and (d) deregulation of immune responses HLA class 1 locus and complement (CD58) [46].

Another mechanism that has been extensively studied is the role of somatic hypermutation (SHM) and class-switch recombination of the immunoglobulin gene in the B cell lymphomagenesis $[47,48]$. These are specifically important in lymphomas in which the germinal center is the source of the cell of origin $[47,48]$. Accumulating evidence has suggested that lymphoma-associated translocations and the activation of other oncogenes are initiated by AID [49].

The mistargeted activity of AID is associated with genetic instability, cell-cycle arrest, and apoptosis [45]. It is postulated that histone/chromatin modification enzymes (active in FL) may permit non-physiologic genomic regions to be accessed by AID, which leads to the generation of secondary genetic mutations. The high expression of AID has been described to be associated with t-FL $[8,18]$.

Regarding the genetic signature, t-FL appears to be closely related to germinal center B cell (GCB)-like DLBCL, as they share common features such as BCL-2 rearrangements, REL amplifications, and mutations in EZH2, GNA13, and TNFRSF14. On the contrary, t-FL shows CDKN2A/B deletions, STAT6 mutations, ARID1A mutations, and FAS mutations/deletions that are rarely seen in de novo DLBCL, which demonstrates its specificity $[18,50]$.

It is important to emphasize that the majority of genetic aberrations that are typical of t-FL can also be observed at a lower frequency in indolent FL $[18,33]$. This finding suggests that a single alteration may not be sufficient to drive transformation and that possibly, a major disruption in the molecular machinery is needed.
AID and to epigenetic mechanisms, especially CREBBP, MLL, EZH2, $\mathrm{H} 3 \mathrm{~K} 4$, and others. Histological transformation is associated with later events such as alterations in CDK2A/B, p53, and MYC. Other alterations are also observed to be part of the transformation process

Additionally, the selective pressure for FL to undergo transformation remains incompletely understood. Carlotti et al. [31] identified clonal evolution in patients who were exposed to different types of treatment, including radiotherapy, chemotherapy, and the "watch and wait" regimen. Pasqualucci et al. [18] also described that mutations do not occur only as a consequence of treatment, considering that untreated patients had been diagnosed with transformation. Therefore, the mutation load should also be considered a complex entity that does not simply reflect a consequence of the treatment or chemotherapy $[18,31]$.

The complex clonal panorama of FL is consistent with its variable and unpredictable clinical behavior [38]. FL tumor cell populations and subpopulations may undergo multiple "transformations" during their lifespan, and it is also probable that they acquire different mutations and presumably distinct sensitivities to therapies $[11,18,31]$.

\section{Diagnosis}

A key problem in t-FL lies with its definition, which relies on the histologic evidence of DLBCL in patients with a previous or concomitant history of FL. Biopsy is still considered the gold standard that is used to document the event [14, 21, 51, 52]; however, in some cases, clinical aspects can be considered convincing enough to conclude that transformation has occurred $[11,19,51,53]$. Notably, many of the initial reports on t-FL were based on the clinical definition of transformation, while the most recent data rely on a stricter pathological definition. The comparison between the cohorts is shown in Table 1 .

The diagnosis of t-FL may be separated into the following aspects:

\section{Clinical}

Higher-grade transformation should be suspected in every FL patient who presents with progression and the fast growth of 


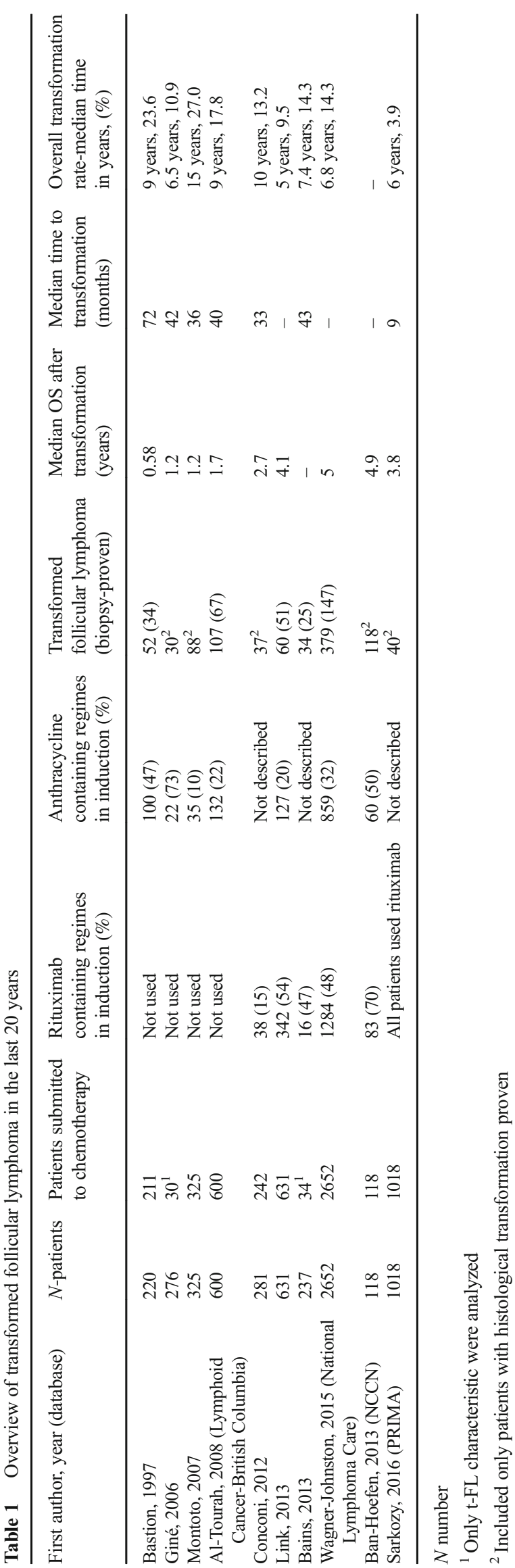

lymph nodes, new extra-nodal sites (i.e., those in the central nervous system, liver, and bone), the development of B symptoms, new hypercalcemia, or the sudden rise in lactate dehydrogenase (LDH). In addition, most patients present with advanced disease (stage III/IV or bulky stage I/II disease) although limited disease may also be associated with transformation [8, 11, 24, 51, 54].

Additionally, time until progression is important, considering that it might be associated with early progression ( $<2$ years after the start of rituximab-based regimens) and transformation. Mozessohn et al. described that transformation was documented in $36.3 \%(8 / 22)$ of cases of early progression [55].

Regarding time to transformation, it has been shown that patients who are diagnosed with transformation early (i.e., at the time of diagnosis or after the first 2 years of follow-up) have better outcomes. Thus, transformation that occurs within 18 months seems to be the worst scenario, as patients exhibit a shorter survival $[19,21]$.

\section{Histopathology}

FL is composed of cells that resemble normal germinal centers, while aggressive lymphomas are characterized by the diffuse proliferation of large cells that efface the follicular architecture $[14,56]$. Biopsy with immunohistochemical examination remains the standard that is used to confirm t-FL. The majority of the transformations show the presence of DLBCL (93\%) or BL (7\%) [51]. Rare histotypes including B lymphoblastic leukemia, plasmablastic lymphoma, and high-grade B cell lymphoma-NOS/with MYC and BCL-2 and/or BCL-6 translocations have also been reported [57-59].

At the time of transformation, $30 \%$ of DLBCL cases are BCL-6-positive, and more than 10\% demonstrate translocation of MYC and BCL-2 in the germinal center [60]. Furthermore, while FL has a low proliferative index, t-FL usually has high Ki-67 expression (staining and transferrin receptor-related protein), which indicates a high proliferative index [56].

The WHO classification [57] also subdivides FL into four grades based on histology (number of centroblasts). Grades 1, 2 , and $3 \mathrm{~A}$ are considered consistent with the morphological spectrum of FL, while grade 3B is considered to be closely related to de novo aggressive lymphoma [57]. Koch et al. analyzed these groups separately and showed that a large proportion of grade 3A FL harbored areas that resembled FL grades $1 / 2$. In contrast, grade $3 \mathrm{~B} F L$ rarely coexists with grade $1 / 2$ or $3 \mathrm{~A} \mathrm{FL}$ and was found to be mostly associated with diffuse growth (DLBCL), which indicates a divergent pathogenesis [61]. This last sub classification, however, seems to be important since grade $3 \mathrm{~A}$ has been linked to an increased risk of transformation $[41,62,63]$. 
Moreover, it is already established that t-FL cannot be morphologically distinguished from de novo DLBCL, and similarly, can be divided into molecular subtypes [41]. As expected, Kridel et al. and Bousaka et al. reported that the majority of t-FL is of the GCB phenotype and that the minority can be identified as the activated $\mathrm{B}$ cell (ABC) type [41, 64]. They also reported that the exceptional t-FL ABC subtype is BCL2-negative, CD10- negative, and IRF-4-positive. These rare molecular alterations tend to co-occur to delineate a distinct molecular pathway and possibly a different entity [41, 65].

Another histological feature of t-FL is that FL and DLBCL can co-occur in the same lymph node and be characterized by a composite histology. This finding implies but does not confirm early transformation. Some authors suggest at least a 6month interval between the initial FL and the DLBCL diagnosis to unequivocally define it as a transformation $[14,53]$.

\section{Imaging}

On the one hand, computed tomography (CT) can help to determine the size of lymph nodes, but this type of scan does not show the metabolic activity of the disease [66]. On the other hand, [18F] fluorodeoxyglucose (FDG)-positron emission tomography (PET-CT) has emerged as a powerful functional imaging tool for staging and response assessment in Hodgkin lymphoma and DLBCL [13, 67, 68].

The Lugano classification recently included PET in the response assessment for indolent lymphoma subtypes, such as FL $[69,70]$. Metabolic response, as defined by PET-CT, was demonstrated to be a strong predictor of OS and PFS after $\mathrm{R}$-induction therapy, and this risk was found to be independent of the FLIPI and FLIPI-2 scores [71].

18F-FDG avidity was also described to be correlated with proliferation levels (Ki-67 expression). A high-standardized uptake value (SUV) on PET-CT in FL may suggest aggressive disease and possible transformation into DLBCL [72]. Studies of indolent lymphomas have reported that an SUV > 10 could predict aggressive lymphoma histology with $80 \%$ certainty, an SUV > 13 with $90 \%$ certainty and an SUV > 17 with $100 \%$ certainty $[73,74]$. Moreover, patients with DLBCL and t-FL showed similar SUV rates $[11,66]$. Noy et al. described that the SUVs in biopsy-proven sites of transformation had a median value of 12 but ranged widely from 3 to 38 . Although the majority of the transformations were associated with a high SUV in this study, many were not. Therefore, transformation might be suspected but not proven with PET-CT. These authors also reaffirmed the recommendation of biopsies of sites with the highest FDG uptake [75].

More importantly, according to this new concept of PET-directed biopsy, it is likely that in the near future, an increasing number of t-FL will emerge; however, the clinical meaning of the discovery of hidden t-FL is not clear and warrants future investigation.

\section{Risk of transformation}

Histological transformation, which remains a rare event in the natural history of FL, ranges from 4 to $27 \%$ (Table 1), and the identification of reliable predictors of transformation at the time of FL diagnosis remains a challenge. The identification of patients who are at high risk for transformation would allow appropriate monitoring, effective treatment, and the development of potential novel therapeutic approaches. Evidence from the literature regarding risk factors of t-FL can be divided into clinical, therapeutic, pathological, and genetic features.

\section{Clinical and treatment-related risk factors}

Until now, clinical factors have been the most important features that are used to predict the risk of transformation [15] (Table 2). The items already described are: elevated beta-2microglobulin levels, high IPI, high FLIPI, and advanced stage (III and IV) [24, 51, 53, 76]. The most recent studies, which were conducted during the rituximab era, described LDH, anemia, an Eastern Cooperation Oncology Group (ECOG) performance status $>1$, and high FLIPI as independent risk factors for transformation [15, 19, 21, 77]. Furthermore, Conconi et al. affirmed the importance of bulky mass and extra-nodal disease, while Sarkozy et al. also suggested $\mathrm{B}$ symptoms and histological grade $3 \mathrm{~A}$ as predictors of transformation $[15,77]$.

With regard to time as a risk factor, some authors have described that transformation seems to be an early event in the natural history of FL, while progression shows a linear risk over time $[15,53]$. Sarkozy described that more than half of HTs in FL were documented during the first year after induction; Link et al. reported a reduction in the risk of HT after 5 years of follow-up $[15,19,53]$. In contrast, other groups have suggested that the risk of transformation over time appears uniform, at least during the first 15 years of follow-up $[51,53]$. Until now, it has not been possible to conclude whether the risk of HT is time-dependent since studies have used different patterns for follow-up, inclusion criteria, and treatments [15].

Different treatment approaches have also been evaluated as risk factors for HT such as expectant management, number of therapies, anthracycline use, and rituximab use. Considering that "watch and wait" is a first-line therapy for FL, Montoto et al., Link et al., and Wagner-Johnston et al. have described that the transformation rates were higher among patients who were primarily observed than those who were initially treated. On the contrary, Conconi et al. found that the "watch and wait" approach was associated with a lower risk of transformation, [19, 21, 24, 77] while Ardeshna et al. in a randomized trial, observed that the risk of transformation was similarly low between the two study arms (observation vs. rituximab) [78]. 
Table 2 Risk factors for transformation

\begin{tabular}{|c|c|c|c|}
\hline & First author, year (database) & Risk factors at diagnosis & Other risk factors \\
\hline \multirow[t]{4}{*}{ Before rituximab era } & Bastion, 1997 & $\begin{array}{l}\text { High B2microglobulin } \\
\text { low albumin levels }\end{array}$ & $\begin{array}{l}\text { Less than } \mathrm{CR} \text { at the end of } \\
\text { treatment induction }\end{array}$ \\
\hline & Giné, 2006 & $\begin{array}{l}\text { Grade } 3 \text { histology } \\
\text { nodal areas }>4 \text {; } \\
\text { high LDH; } \\
\text { high B2microglobulin; } \\
\text { high IPI; } \\
\text { high FLIPI }^{1}\end{array}$ & $\begin{array}{l}\text { Less than } \mathrm{CR} \text { at the end of } \\
\text { treatment induction }\end{array}$ \\
\hline & Montoto, 2007 & $\begin{array}{l}\text { Advanced stages; } \\
\text { high FLIPI; } \\
\text { high IPI }\end{array}$ & $\begin{array}{l}\text { Expectant management as } \\
\text { initial therapy }\end{array}$ \\
\hline & $\begin{array}{l}\text { Al-Tourah, } 2008 \text { (Lymphoid } \\
\text { Cancer-British Columbia) }\end{array}$ & Advanced stage $^{1}$ & $\begin{array}{l}\text { Multiples lines of therapy alkylator } \\
\text { with purine analogue }\end{array}$ \\
\hline \multirow[t]{4}{*}{ After rituximab era } & Conconi, 2012 & $\begin{array}{l}\text { Bulky }^{1} \text {; } \\
\text { extranodal disease }^{1}\end{array}$ & R-chemo increased the risk \\
\hline & Link, 2013 & $\begin{array}{l}\mathrm{LDH}^{1} \\
\text { anemia }(\mathrm{Hb}<12) \\
\text { FLIPI }\end{array}$ & $\begin{array}{l}\text { Expectant management as } \\
\text { initial therapy }\end{array}$ \\
\hline & $\begin{array}{l}\text { Wagner-Johnston, } 2015 \\
\text { (National Lymphoma Care) }\end{array}$ & $\begin{array}{l}\text { ECOG }>1^{1} ; \text { extranodal sites }>1^{1} ; \\
\text { high } \mathrm{LDH}^{1} ; \text { B symptoms }\end{array}$ & $\begin{array}{l}\text { Expectant management as } \\
\text { initial therapy }\end{array}$ \\
\hline & Sarkozy, 2016 (PRIMA) & $\begin{array}{l}\text { ECOG }^{1} \text {; } \\
\text { anemia } \\
\text { high LDH; } \\
\text { B symptoms; } \\
\text { high FLIPI score; } \\
\text { grade 3A }\end{array}$ & \\
\hline
\end{tabular}

CR complete response, $L D H$ lactate dehydrogenase, IPI International Prognostic Index, FLIPI Follicular Lymphoma International Prognostic Index

${ }^{1}$ Independent factors in multivariate analysis

With respect to treatment outcomes, patients were described to be at a higher risk if they did not achieve complete response at the end of induction therapy [53, 76]. However, Sarkozy et al. described that the quality of the response did not impact the risk of transformation [15]. In addition, no consensus exists in the literature regarding the use of anthracycline. Some authors have suggested no correlation $[15,19,21]$, while others have reported lower risk with the use of this drug [51].

Rituximab, as part of induction therapy and based on either retrospective [19, 21, 51, 79] or clinical trials data [15], has been suggested to reduce the risk of transformation, especially when used as a maintenance therapy. These latest studies clarified previous questions with respect to the benefits of rituximab [78].

\section{Pathological and genetic risk factors}

Pathological and genetic factors are emerging as novel predictors of risk, but the literature remains contradictory in some aspects, and these new biomarkers need to be validated in large prospective cohorts [33].

Considering the pathological findings, the grading of FL has been associated with survival and transformation. Despite this, high-grade FL has historically been associated with poor survival [57], but the most recent studies have shown a better outcome for grade 3A/B FL [80]. Grade 3A has also been linked to an increased incidence of transformation in some studies, and both $3 \mathrm{~A} / \mathrm{B}$ have been associated with certain molecular findings that have been described as risk factors for transformation, such as BCL-6 translocation, absence of prototypical BCL-2 translocation, and/or positive expression of IRF4 [41, 62, 63].

The immunohistochemical assessment of IRF4 warrants special attention since it is associated with a worse prognosis, poor progression-free survival (PFS), high proliferation rates, and transformation $[41,63,81]$. This protein deserves further validation but has a plausible potential to predict transformation [33].

Genetic features represent another means to predict transformation risks. The alterations that have been described in the literature thus far are chromosomal changes (i.e., segmental deletions within $1 p$ and $6 p$ or gains involving $2,3 q$, and 5) [82-85], somatic gene mutations such as those in the BCL-6 gene [86] and BCL-2 gene [8, 87] and MYC rearrangements [43]. Other alterations include the loss of heterozygosity or mutations in Tp53 [88, 89], deregulation of MDM2 (key p53 regulator) [88], and inactivation of $\mathrm{CDKN} 2 \mathrm{~A} / \mathrm{B}$ by deletion mutations and hypermethylation [90]. 
As has been described previously, other individual genes have also been studied. Consequently, Pastore et al. proposed a risk model (m7-FLIPI) that combines the mutational status of seven genes (EZH2, ARID1A, MEF2B, EP300, FOXO1, CREBBP, and CARD11) into a predictive score that also includes the FLIPI and ECOG performance status. This model introduces a new concept for risk stratification in FL and is a promising approach that may be used to identify the subset of FL patients at highest risk for treatment failure. Although no data have been generated regarding transformation in this risk model, m7-FLIPI may be a promising marker that can be used in risk stratification for transformation $[33,91]$.

\section{Treatment}

\section{Treatment and outcome in historical series}

In initial studies, the outcome of t-FL patients was very poor, with a median OS of approximately 1 or 2 years [24]. However, the majority of published studies were conducted in the prerituximab era. Most recent studies have confirmed the improvement of OS in patients with t-FL in the rituximab era (as part of induction and post-transformation therapy) $[19,53,79]$.

The study conducted by Link and colleagues found that in 60 out of 631 patients with biopsy-proven t-FL, the OS rate was $73 \%$ at 5 years after treatment with rituximab-based chemotherapy [18]. The results seen in patients with early-stage FL (treated with radiotherapy only) who experienced transformation were equivalent. The 3-year OS post-transformation was 87 vs. $38.5 \%$ for R-chemotherapy and chemotherapy alone, respectively [92].

The R-CHOP regimen is still currently considered a good option with which to treat t-FL, especially anthracycline-naïve patients. It is known that some t-FL cohorts have responded extremely well with only R-chemotherapy [19, 21, 93].
Additionally, Link et al. showed that after transformation, the outcomes were indistinguishable when compared with those of patients with de novo DLBCL and anthracyclinenaïve transformed FL [19].

Therefore, the role of autologous stem cell transplantation (ASCT) in the rituximab era does not seem to be mandatory [19]. Wagner-Johnston et al. reported that only a few t-FL patients have undergone ASCT, which reaffirms this idea $[21,94]$.

Despite the controversy surrounding ASCT, this therapy can be considered part of the treatment for eligible patients with t-FL, especially those who have already been exposed to anthracyclines. In studies from the pre-rituximab era, in patients with chemosensitive transformed lymphoma, the 5 -year OS and PFS rates after ASCT were 51 and 30\%, respectively, which suggests a long-term benefit of this management strategy [95].

With regard to ASCT in the rituximab era, this approach has been shown to improve the outcomes of t-FL in some studies; Table 3 summarizes the major studies that have been conducted in the rituximab era. The Canadian Bone Marrow Transplant Group (CBMTG) showed better outcomes (OS and PFS) for those treated with additional ASCT, even though this difference was modest at 5 years (OS 65\% with ASCT; $61 \%$ with chemoimmunotherapy; $p<0.001$ ) [96].

Ban-Hoefen et al. (NCCN database) also suggested a benefit of ASCT in the rituximab era. The 2-year OS was $74 \%$ for patients who underwent ASCT, while for those who did not, the 2-year OS was 59\%. This group also emphasized that patients who were chemotherapy-naïve prior to ASCT seemed to achieve better results [22].

For post-ASCT relapses, a few options exist including novel regimens (in the context of clinical trials) and possibly salvage therapy with allogeneic transplantation (AlloSCT) for highly selected patients [97, 98]. However, AlloSCT in t-FL has not been well-studied, and studies to date have been

Table 3 Studies that have evaluated ASCT or allogeneic transplant in transformed follicular lymphoma in the rituximab era

\begin{tabular}{|c|c|c|c|c|c|c|}
\hline First author, year (database) & ASCT or allo & $\begin{array}{l}\text { Number } \\
\text { of patients }\end{array}$ & $\begin{array}{l}\text { Median age at } \\
\text { transplantation } \\
\text { (years) }\end{array}$ & $\begin{array}{l}\text { OS, } \\
(\%)\end{array}$ & $\begin{array}{l}\text { PFS or EFS, } \\
(\%)\end{array}$ & $\begin{array}{l}\text { Median follow-up } \\
\text { (years) }\end{array}$ \\
\hline Smith, 2009 & ASCT & 25 & 57 & 3 years, 63 & 3 years, 64 & 2.1 \\
\hline \multirow[t]{2}{*}{ Reddy, 2012} & ASCT & 12 & 61 & 5 years, 91.7 & 5 years, 73.3 & 6 \\
\hline & Allo & 23 & 52 & 5 years, 53.9 & 5 years, 43 & 6 \\
\hline $\begin{array}{l}\text { Ban-Hoefen, } 2012 \\
\text { (National Comprehensive Cancer } \\
\quad \text { Network-Database) }\end{array}$ & ASCT & $18^{1}$ & 58 & 2 years, 82 & 2 years, 59 & 3.3 \\
\hline Villa, 2013 & ASCT & 97 & 56 & 5 years, 65 & 5 years, 55 & 7.5 \\
\hline $\begin{array}{l}\text { (Canadian Bone Marrow } \\
\text { Transplant Group) }\end{array}$ & Allo & 22 & 48 & 5 years, 46 & 5 years, 46 & 7.5 \\
\hline
\end{tabular}

$O S$ overall survival, $P F S$ progression-free survival, $E F S$ event-free survival

${ }^{1}$ Included two patients with marginal zone lymphoma and six patients did not received rituximab as an induction therapy 
performed in small cohorts and have involved short followups and significant transplant-related mortality. Reddy et al. compared AlloSCT to ASCT and observed an important difference between these groups. The 5-year post-transplant OS was 53 vs. $91.7 \%$, while the PFS was 43 vs. $73.3 \%$, for the AlloSCT and ASCT groups, respectively. However, Villa et al. (Canadian Bone Marrow Transplant Group) described an OS of 46 vs. $65 \%$ and a PFS of 46 vs. $55 \%$ for the AlloSCT and the ASCT groups, respectively, at 5-year post-transplant $[96,99]$. Therefore, the AlloSCT series demonstrated an inferior result compared with that of ASCT, which was due in part to high treatment-related mortality ( 35 vs. $10 \%$ at 5 years, respectively) and also to heavily pre-treatment conditions [100]. On the contrary, the risk for disease relapse at 5 years was lower in the AlloSCT group, but it is important to consider that those patients comprised a highly selected group [22].

\section{Current management}

Our approach to the management of t-FL begins with the correct diagnosis, which reinforces the importance of biopsy at the time transformation is suspected. A PET-CT-guided biopsy may be useful in this scenario. After the diagnosis is confirmed, subsequent decisions would be made based on the age, comorbidities, and performance status of the patient. In both young and old patients who are physically fit, it is important to clarify whether they have been exposed to previous treatments with anthracycline-based regimens. If patients were previously exposed, they should undergo salvage chemotherapy (platinum-containing chemotherapy) and ASCT; however, if the patients are anthracycline-naïve, they should receive R-CHOP. ASCT can be discussed, but it is not mandatory. For older unfit patients who have received anthracycline or are too frail to tolerate full-dose chemotherapy, the regimens suggested are mini-CHOP [101] or nonanthracycline-containing regimens such R-GCVP [102]. Clinical trials are strongly encouraged in this situation, especially with the new available single-agent lenalidomide [103], venetoclax [104], ibrutinib [105], and idelalisib [106, 107].

\section{Novel regimens}

Novel agents have also been investigated in t-FL. In a phase 2 study, lenalidomide showed an overall response rate of $57 \%$, with a median response duration of over 1 year in t-FL patients [103]. Specific inhibitors that target Aurora A kinase (alisertib) [108], Bruton tyrosine kinase (ibrutinib) [105], the $\vartheta$ isoform of phosphatidylinositol 3-kinase (idelalisib) [106, 107], and BCL-2 protein (GDC-0199/ABT199—venetoclax) [104] are currently being investigated in both indolent and aggressive lymphomas. These novel agents seem to have a significant impact on the outcome of t-FL patients.

\section{Conclusion}

HT of indolent lymphoma has been randomly studied over the years, and even now, many are concerned considering the morbidity and mortality rates of t-FL. The incidence varies among different series and according to different definitions of HT and treatment approaches. Most available data are derived from retrospective studies, whereas risk factors and therapeutic strategies are not completely standardized. Furthermore, the most recent data suggest that rituximab (induction or maintenance) is associated with better outcomes and lower risks of transformation. Further studies are still necessary to clarify the biology of transformation as well as the identification of biomarkers, which might be future potential targets for individualized treatment of t-FL.

\section{Compliance with ethical standards}

Conflict of interest The authors declare that they have no conflict of interest.

\section{References}

1. Harris NL, Jaffe ES, Stein H, Banks PM, Chan JK, Cleary ML et al (1994) A revised European-American classification of lymphoid neoplasms: a proposal from the International Lymphoma Study Group. Blood 84(5):1361-1392

2. Harris NL, Jaffe ES, Diebold J, Flandrin G, Muller-Hermelink HK, Vardiman J et al (1999) World Health Organization classification of neoplastic diseases of the hematopoietic and lymphoid tissues: report of the Clinical Advisory Committee meeting-Airlie House, Virginia, November 1997. J Clin Oncol 17(12):38353849. https://doi.org/10.1200/JCO.1999.17.12.3835

3. Jaglowski SM, Linden E, Termuhlen AM, Flynn JM (2009) Lymphoma in adolescents and young adults. Semin Oncol 36(5):381-418. https://doi.org/10.1053/j.seminoncol.2009.07. 009

4. Zelenetz AD, Abramson JS, Advani RH, Andreadis CB, Bartlett N, Bellam N et al (2011) Non-Hodgkin's lymphomas. J Natl Compr Cancer Netw 9(5):484-560

5. Junlen HR, Peterson S, Kimby E, Lockmer S, Linden O, NilssonEhle H et al (2015) Follicular lymphoma in Sweden: nationwide improved survival in the rituximab era, particularly in elderly women: a Swedish Lymphoma Registry study. Leukemia 29(3): 668-676. https://doi.org/10.1038/leu.2014.251

6. Bilalovic N, Blystad AK, Golouh R, Nesland JM, Selak I, Trinh D et al (2004) Expression of bcl-6 and CD10 protein is associated with longer overall survival and time to treatment failure in follicular lymphoma. Am J Clin Pathol 121(1):34 42. https://doi.org/ 10.1309/TNKL-7GDC-66R9-WPV5

7. Swenson WT, Wooldridge JE, Lynch CF, Forman-Hoffman VL, Chrischilles E, Link BK (2005) Improved survival of follicular lymphoma patients in the United States. J Clin Oncol 23(22): 5019-5026. https://doi.org/10.1200/JCO.2005.04.503

8. Correia C, Schneider PA, Dai H, Dogan A, Maurer MJ, Church AK et al (2015) BCL2 mutations are associated with increased risk of transformation and shortened survival in follicular lymphoma. Blood 125(4):658-667. https://doi.org/10.1182/blood-2014-04571786 
9. Weiss LM, Warnke RA, Sklar J, Cleary ML (1987) Molecular analysis of the $t(14 ; 18)$ chromosomal translocation in malignant lymphomas. N Engl J Med 317(19):1185-1189. https://doi.org/ 10.1056/NEJM198711053171904

10. Rowley JD (1988) Chromosome studies in the non-Hodgkin's lymphomas: the role of the $14 ; 18$ translocation. J Clin Oncol 6(5):919-925. https://doi.org/10.1200/JCO.1988.6.5.919

11. Casulo C, Burack WR, Friedberg JW (2015) Transformed follicular non-Hodgkin lymphoma. Blood 125(1):40-47. https://doi. org/10.1182/blood-2014-04-516815

12. Lambrechts AC, Hupkes PE, Dorssers LC, van't Veer MB (1993) Translocation (14;18)-positive cells are present in the circulation of the majority of patients with localized (stage I and II) follicular non-Hodgkin's lymphoma. Blood 82(8):2510-2516

13. Trotman J, Luminari S, Boussetta S, Versari A, Dupuis J, Tychyj C et al (2014) Prognostic value of PET-CT after first-line therapy in patients with follicular lymphoma: a pooled analysis of central scan review in three multicentre studies. Lancet Haematol 1(1): e17-e27. https://doi.org/10.1016/S2352-3026(14)70008-0

14. Lossos IS, Gascoyne RD (2011) Transformation of follicular lymphoma. Best Pract Res Clin Haematol 24(2):147-163. https://doi. org/10.1016/j.beha.2011.02.006

15. Sarkozy C, Trneny M, Xerri L, Wickham N, Feugier P, Leppa S et al (2016) Risk factors and outcomes for patients with follicular lymphoma who had histologic transformation after response to first-line immunochemotherapy in the PRIMA trial. J Clin Oncol 34(22):2575-2582. https://doi.org/10.1200/JCO.2015.65.7163

16. Rummel MJ, Niederle N, Maschmeyer G, Banat GA, von Grunhagen U, Losem C et al (2013) Bendamustine plus rituximab versus CHOP plus rituximab as first-line treatment for patients with indolent and mantle-cell lymphomas: an open-label, multicentre, randomised, phase 3 non-inferiority trial. Lancet 381(9873):1203-1210. https://doi.org/10.1016/S0140-6736(12) 61763-2

17. Cheung KJ, Johnson NA, Affleck JG, Severson T, Steidl C, BenNeriah S et al (2010) Acquired TNFRSF14 mutations in follicular lymphoma are associated with worse prognosis. Cancer Res 70(22):9166-9174. https://doi.org/10.1158/0008-5472.CAN-102460

18. Pasqualucci L, Khiabanian H, Fangazio M, Vasishtha M, Messina $\mathrm{M}$, Holmes AB et al (2014) Genetics of follicular lymphoma transformation. Cell Rep 6(1):130-140. https://doi.org/10.1016/j. celrep.2013.12.027

19. Link BK, Maurer MJ, Nowakowski GS, Ansell SM, Macon WR, Syrbu SI et al (2013) Rates and outcomes of follicular lymphoma transformation in the immunochemotherapy era: a report from the University of Iowa/MayoClinic specialized program of research excellence molecular epidemiology resource. J Clin Oncol 31(26): 3272-3278. https://doi.org/10.1200/JCO.2012.48.3990

20. Lossos IS, Levy R (2003) Higher grade transformation of follicular lymphoma: phenotypic tumor progression associated with diverse genetic lesions. Semin Cancer Biol 13(3):191-202

21. Wagner-Johnston ND, Link BK, Byrtek M, Dawson KL, Hainsworth J, Flowers CR et al (2015) Outcomes of transformed follicular lymphoma in the modern era: a report from the National LymphoCare Study (NLCS). Blood 126(7):851-857. https://doi. org/10.1182/blood-2015-01-621375

22. Ban-Hoefen M, Vanderplas A, Crosby-Thompson AL, Abel GA, Czuczman MS, Gordon LI et al (2013) Transformed non-Hodgkin lymphoma in the rituximab era: analysis of the NCCN outcomes database. Br J Haematol 163(4):487-495. https://doi.org/10.1111/ bjh. 12570

23. Salles G, Seymour JF, Offner F, Lopez-Guillermo A, Belada D, Xerri L et al (2011) Rituximab maintenance for 2 years in patients with high tumour burden follicular lymphoma responding to rituximab plus chemotherapy (PRIMA): a phase 3, randomised controlled trial. Lancet 377(9759):42-51. https://doi.org/10. 1016/S0140-6736(10)62175-7

24. Montoto S, Davies AJ, Matthews J, Calaminici M, Norton AJ, Amess J et al (2007) Risk and clinical implications of transformation of follicular lymphoma to diffuse large B-cell lymphoma. J Clin Oncol 25(17):2426-2433. https://doi.org/10.1200/JCO.2006. 09.3260

25. Cullen MH, Lister TA, Brearley RI, Shand WS, Stansfeld AG (1979) Histological transformation of non-Hodgkin's lymphoma: a prospective study. Cancer 44(2):645-651

26. Lossos IS, Alizadeh AA, Diehn M, Warnke R, Thorstenson Y, Oefner PJ et al (2002) Transformation of follicular lymphoma to diffuse large-cell lymphoma: alternative patterns with increased or decreased expression of c-myc and its regulated genes. Proc Natl Acad Sci U S A 99(13):8886-8891. https://doi.org/10.1073/pnas. 132253599

27. Lossos IS, Warnke R, Levy R (2002) BCL-6 mRNA expression in higher grade transformation of follicle center lymphoma: correlation with somatic mutations in the $5^{\prime}$ regulatory region of the BCL6 gene. Leukemia 16(9):1857-1862. https://doi.org/10.1038/sj. leu. 2402578

28. Martinez-Climent JA, Alizadeh AA, Segraves R, Blesa D, RubioMoscardo F, Albertson DG et al (2003) Transformation of follicular lymphoma to diffuse large cell lymphoma is associated with a heterogeneous set of DNA copy number and gene expression alterations. Blood 101(8):3109-3117. https://doi.org/10.1182/ blood-2002-07-2119

29. Gall EA, Mallory TB (1942) Malignant lymphoma: a clinicopathologic survey of 618 cases. Am J Pathol 18(3):381-429

30. Montoto S, Fitzgibbon J (2011) Transformation of indolent B-cell lymphomas. J Clin Oncol 29(14):1827-1834. https://doi.org/10. 1200/JCO.2010.32.7577

31. Carlotti E, Wrench D, Matthews J, Iqbal S, Davies A, Norton A et al (2009) Transformation of follicular lymphoma to diffuse large B-cell lymphoma may occur by divergent evolution from a common progenitor cell or by direct evolution from the follicular lymphoma clone. Blood 113(15):3553-3557. https://doi.org/10.1182/ blood-2008-08-174839

32. Al-Hajj M, Wicha MS, Benito-Hernandez A, Morrison SJ, Clarke MF (2003) Prospective identification of tumorigenic breast cancer cells. Proc Natl Acad Sci U S A 100(7):3983-3988. https://doi. org/10.1073/pnas.0530291100

33. Kridel R, Sehn LH, Gascoyne RD (2017) Can histologic transformation of follicular lymphoma be predicted and prevented? Blood. https://doi.org/10.1182/blood-2017-03-691345

34. Maeshima AM, Omatsu M, Nomoto J, Maruyama D, Kim SW, Watanabe T et al (2008) Diffuse large B-cell lymphoma after transformation from low-grade follicular lymphoma: morphological, immunohistochemical, and FISH analyses. Cancer Sci 99(9): 1760-1768. https://doi.org/10.1111/j.1349-7006.2008.00873.x

35. Ladetto M, Drandi D, Compagno M, Astolfi M, Volpato F, Voena $\mathrm{C}$ et al (2003) PCR-detectable nonneoplastic Bcl-2/IgH rearrangements are common in normal subjects and cancer patients at diagnosis but rare in subjects treated with chemotherapy. J Clin Oncol 21(7):1398-1403. https://doi.org/10.1200/JCO.2003.07.070

36. Dolken G, Illerhaus G, Hirt C, Mertelsmann R (1996) BCL-2/JH rearrangements in circulating $\mathrm{B}$ cells of healthy blood donors and patients with nonmalignant diseases. J Clin Oncol 14(4):13331344. https://doi.org/10.1200/JCO.1996.14.4.1333

37. Yasukawa M, Bando S, Dolken G, Sada E, Yakushijin Y, Fujita S et al (2001) Low frequency of BCL-2/J(H) translocation in peripheral blood lymphocytes of healthy Japanese individuals. Blood 98(2):486-488

38. Green MR, Gentles AJ, Nair RV, Irish JM, Kihira S, Liu CL et al (2013) Hierarchy in somatic mutations arising during genomic 
evolution and progression of follicular lymphoma. Blood 121(9): 1604-1611. https://doi.org/10.1182/blood-2012-09-457283

39. Pasqualucci L, Dominguez-Sola D, Chiarenza A, Fabbri G, Grunn A, Trifonov $\mathrm{V}$ et al (2011) Inactivating mutations of acetyltransferase genes in B-cell lymphoma. Nature 471(7337):189-195. https://doi.org/10.1038/nature09730

40. Sherry MA, Best TM (2004) A comparison of 2 rehabilitation programs in the treatment of acute hamstring strains. J Orthop Sports Phys Ther 34(3):116-125. https://doi.org/10.2519/jospt. 2004.34.3.116

41. Kridel R, Mottok A, Farinha P, Ben-Neriah S, Ennishi D, Zheng Y et al (2015) Cell of origin of transformed follicular lymphoma. Blood 126(18):2118-2127. https://doi.org/10.1182/blood-201506-649905

42. Ramiro AR, Jankovic M, Eisenreich T, Difilippantonio S, ChenKiang S, Muramatsu M et al (2004) AID is required for c-myc/IgH chromosome translocations in vivo. Cell 118(4):431-438. https:// doi.org/10.1016/j.cell.2004.08.006

43. Yano T, Jaffe ES, Longo DL, Raffeld MMYC (1992) Rearrangements in histologically progressed follicular lymphomas. Blood 80(3): 758-767

44. Akasaka T, Lossos IS, Levy R (2003) BCL6 gene translocation in follicular lymphoma: a harbinger of eventual transformation to diffuse aggressive lymphoma. Blood 102(4):1443-1448. https:// doi.org/10.1182/blood-2002-08-2482

45. Shikata H, Yakushijin Y, Matsushita N, Sakai A, Sugita A, Nakamura $\mathrm{N}$ et al (2012) Role of activation-induced cytidine deaminase in the progression of follicular lymphoma. Cancer Sci 103(3):415-421. https://doi.org/10.1111/j.1349-7006.2011. 02186.x

46. Challa-Malladi M, Lieu YK, Califano O, Holmes AB, Bhagat G, Murty VV et al (2011) Combined genetic inactivation of beta2microglobulin and CD58 reveals frequent escape from immune recognition in diffuse large B cell lymphoma. Cancer Cell 20(6): 728-740. https://doi.org/10.1016/j.ccr.2011.11.006

47. Smit LA, Bende RJ, Aten J, Guikema JE, Aarts WM, van Noesel CJ (2003) Expression of activation-induced cytidine deaminase is confined to B-cell non-Hodgkin's lymphomas of germinal-center phenotype. Cancer Res 63(14):3894-3898

48. Hardianti MS, Tatsumi E, Syampurnawati M, Furuta K, Saigo K, Nakamachi Y et al (2004) Activation-induced cytidine deaminase expression in follicular lymphoma: association between AID expression and ongoing mutation in FL. Leukemia 18(4):826-831. https://doi.org/10.1038/sj.leu.2403323

49. Perez-Duran P, de Yebenes VG, Ramiro AR (2007) Oncogenic events triggered by AID, the adverse effect of antibody diversification. Carcinogenesis 28(12):2427-2433. https://doi.org/10. 1093/carcin/bgm201

50. Pasqualucci L, Trifonov V, Fabbri G, Ma J, Rossi D, Chiarenza A et al (2011) Analysis of the coding genome of diffuse large B-cell lymphoma. Nat Genet 43(9):830-837. https://doi.org/10.1038/ng. 892

51. Al-Tourah AJ, Gill KK, Chhanabhai M, Hoskins PJ, Klasa RJ, Savage KJ et al (2008) Population-based analysis of incidence and outcome of transformed non-Hodgkin's lymphoma. J Clin Oncol 26(32):5165-5169. https://doi.org/10.1200/JCO.2008.16. 0283

52. Tellier J, Menard C, Roulland S, Martin N, Monvoisin C, Chasson $\mathrm{L}$ et al (2014) Human $\mathrm{t}(14 ; 18)$ positive germinal center B cells: a new step in follicular lymphoma pathogenesis? Blood 123(22): 3462-3465. https://doi.org/10.1182/blood-2013-12-545954

53. Bastion Y, Sebban C, Berger F, Felman P, Salles G, Dumontet C et al (1997) Incidence, predictive factors, and outcome of lymphoma transformation in follicular lymphoma patients. J Clin Oncol 15(4):1587-1594. https://doi.org/10.1200/JCO.1997.15.4.1587
54. Yuen AR, Kamel OW, Halpern J, Horning SJ (1995) Long-term survival after histologic transformation of low-grade follicular lymphoma. J Clin Oncol 13(7):1726-1733

55. Mozessohn L, Cheung MC, Crump M, Buckstein R, Berinstein N, Imrie K et al (2014) Chemoimmunotherapy resistant follicular lymphoma: predictors of resistance, association with transformation and prognosis. Leuk Lymphoma 55(11):2502-2507. https:// doi.org/10.3109/10428194.2014.885513

56. Natkunam Y, Soslow R, Matolcsy A, Dolezal M, Bhargava V, Knowles DM et al (2004) Immunophenotypic and genotypic characterization of progression in follicular lymphomas. Appl Immunohistochem Mol Morphol 12(2):97-104

57. Swerdlow SH, Campo E, Pileri SA, Harris NL, Stein H, Siebert R et al (2016) The 2016 revision of the World Health Organization classification of lymphoid neoplasms. Blood 127(20):2375-2390. https://doi.org/10.1182/blood-2016-01-643569

58. Ouansafi I, He B, Fraser C, Nie K, Mathew S, Bhanji R et al (2010) Transformation of follicular lymphoma to plasmablastic lymphoma with c-myc gene rearrangement. Am J Clin Pathol 134(6):972-981. https://doi.org/10.1309/AJCPWY1SGJ9IEAOR

59. Ning Y, Foss A, Kimball AS, Neill N, Matz T, Schultz R (2013) Characterization of a case of follicular lymphoma transformed into B-lymphoblastic leukemia. Mol Cytogenet 6(1):34. https://doi. org/10.1186/1755-8166-6-34

60. Jaffe ES, Pittaluga S (2011) Aggressive B-cell lymphomas: a review of new and old entities in the WHO classification. Hematol Am Soc Hematol Educ Program 2011:506-514. https://doi.org/ 10.1182/asheducation-2011.1.506

61. Koch K, Hoster E, Ziepert M, Unterhalt M, Ott G, Rosenwald A et al (2016) Clinical, pathological and genetic features of follicular lymphoma grade 3A: a joint analysis of the German low-grade and high-grade lymphoma study groups GLSG and DSHNHL. Ann Oncol 27(7):1323-1329. https://doi.org/10.1093/annonc/mdw185

62. Gollub W, Stassek B, Huckhagel T, Bernd HW, Krokowski M, Merz H et al (2009) BCL6-translocations affect the phenotype of follicular lymphomas only in the absence of $\mathrm{t}(14 ; 18) \operatorname{IgH} / \mathrm{BCL} 2$. Anticancer Res 29(11):4649-4655

63. Xerri L, Bachy E, Fabiani B, Canioni D, Chassagne-Clement C, Dartigues-Cuilleres P et al (2014) Identification of MUM1 as a prognostic immunohistochemical marker in follicular lymphoma using computerized image analysis. Hum Pathol 45(10):20852093. https://doi.org/10.1016/j.humpath.2014.06.019

64. Bouska A, McKeithan TW, Deffenbacher KE, Lachel C, Wright GW, Iqbal J et al (2014) Genome-wide copy-number analyses reveal genomic abnormalities involved in transformation of follicular lymphoma. Blood 123(11):1681-1690. https://doi.org/10. 1182/blood-2013-05-500595

65. Karube K, Guo Y, Suzumiya J, Sugita Y, Nomura Y, Yamamoto K et al (2007) CD10-MUM1+ follicular lymphoma lacks BCL2 gene translocation and shows characteristic biologic and clinical features. Blood 109(7):3076-3079. https://doi.org/10.1182/blood2006-09-045989

66. Novelli S, Briones J, Flotats A, Sierra J (2015) PET/CT assessment of follicular lymphoma and high grade B cell lymphoma - good correlation with clinical and histological features at diagnosis. Adv Clin Exp Med 24(2):325-330. https://doi.org/10.17219/acem/31804

67. Luminari S, Biasoli I, Arcaini L, Versari A, Rusconi C, Merli F et al (2013) The use of FDG-PET in the initial staging of 142 patients with follicular lymphoma: a retrospective study from the FOLL05 randomized trial of the Fondazione Italiana Linfomi. Ann Oncol 24(8):2108-2112. https://doi.org/10.1093/annonc/ mdt137

68. Iwamuro M, Okada H, Takata K, Shinagawa K, Fujiki S, Shiode J et al (2012) Diagnostic role of 18F-fluorodeoxyglucose positron emission tomography for follicular lymphoma with 
gastrointestinal involvement. World J Gastroenterol 18(44):64276436; discussion p 6434. https://doi.org/10.3748/wjg.v18.i44. 6427

69. Cheson BD, Fisher RI, Barrington SF, Cavalli F, Schwartz LH, Zucca E et al (2014) Recommendations for initial evaluation, staging, and response assessment of Hodgkin and non-Hodgkin lymphoma: the Lugano classification. J Clin Oncol 32(27):30593068. https://doi.org/10.1200/JCO.2013.54.8800

70. Barrington SF, Mikhaeel NG, Kostakoglu L, Meignan M, Hutchings M, Mueller SP et al (2014) Role of imaging in the staging and response assessment of lymphoma: consensus of the International Conference on Malignant Lymphomas Imaging Working Group. J Clin Oncol 32(27):3048-3058. https://doi. org/10.1200/JCO.2013.53.5229

71. Wong-Sefidan I, Byrtek M, Zhou X, Friedberg JW, Flowers CR, Zelenetz AD et al (2017) [18F] Positron emission tomography response after rituximab-containing induction therapy in follicular lymphoma is an independent predictor of survival after adjustment for FLIPI in academic and community-based practice. Leuk Lymphoma 58(4):809-815. https://doi.org/10.1080/10428194. 2016.1213824

72. Yildiz M, Li H, Bernard D, Amin NA, Ouillette P, Jones S et al (2015) Activating STAT6 mutations in follicular lymphoma. Blood 125(4):668-679. https://doi.org/10.1182/blood-2014-06582650

73. Schoder H, Noy A, Gonen M, Weng L, Green D, Erdi YE et al (2005) Intensity of 18 fluorodeoxyglucose uptake in positron emission tomography distinguishes between indolent and aggressive non-Hodgkin's lymphoma. J Clin Oncol 23(21):4643-4651. https://doi.org/10.1200/JCO.2005.12.072

74. Bodet-Milin C, Kraeber-Bodere F, Moreau P, Campion L, Dupas B, Le Gouill S (2008) Investigation of FDG-PET/CT imaging to guide biopsies in the detection of histological transformation of indolent lymphoma. Haematologica 93(3):471-472. https://doi. org/10.3324/haematol.12013

75. Noy A, Schoder H, Gonen M, Weissler M, Ertelt K, Cohler C et al (2009) The majority of transformed lymphomas have high standardized uptake values (SUVs) on positron emission tomography (PET) scanning similar to diffuse large B-cell lymphoma (DLBCL). Ann Oncol 20(3):508-512. https://doi.org/10.1093/ annonc/mdn 657

76. Gine E, Montoto S, Bosch F, Arenillas L, Mercadal S, Villamor N et al (2006) The Follicular Lymphoma International Prognostic Index (FLIPI) and the histological subtype are the most important factors to predict histological transformation in follicular lymphoma. Ann Oncol 17(10):1539-1545. https://doi.org/10.1093/ annonc/mdl162

77. Conconi A, Ponzio C, Lobetti-Bodoni C, Motta M, Rancoita PM, Stathis A et al (2012) Incidence, risk factors and outcome of histological transformation in follicular lymphoma. Br J Haematol 157(2):188-196. https://doi.org/10.1111/j.1365-2141.2012. 09054.x

78. Ardeshna KM, Qian W, Smith P, Braganca N, Lowry L, Patrick P et al (2014) Rituximab versus a watch-and-wait approach in patients with advanced-stage, asymptomatic, non-bulky follicular lymphoma: an open-label randomised phase 3 trial. Lancet Oncol 15(4):424-435. https://doi.org/10.1016/S1470-2045(14) 70027-0

79. Federico M CD, Marcheselli L, Tarantino V, Sarkozy C, Lopez Guillermo A, Wondergem M, Kimby E, Rusconi C,. Zucca E, Montoto S, da Silva MG, Aurer I, Paszkiewicz-Kozik E, Cartron G, Morschhauser F, Alcoceba M, Chamuleau M, Lockmer S, Minoia C, Issa D, Alonso S, Conte L, Salles G, Coiffier B (2017) The risk of transformation offollicular lymphoma"transformed" by rituximab: the Aristotle study promoted by the European Lymphoma Institute. Hematol Oncol 35, issue supplement S2(June 2017): 115-116. e-pub ahead of print http://onlinelibrary.wiley.com/doi/10.1002/hon.2437 104/e.pdf;

80. Wahlin BE, Sundstrom C, Sander B, Christensson B, JeppssonAhlberg A, Hjalmarsson E et al (2014) Higher World Health Organization grades of follicular lymphoma correlate with better outcome in two Nordic Lymphoma Group trials of rituximab without chemotherapy. Leuk Lymphoma 55(2):288-295. https:/doi. org/10.3109/10428194.2013.802778

81. Sweetenham JW, Goldman B, LeBlanc ML, Cook JR, Tubbs RR, Press OW et al (2010) Prognostic value of regulatory T cells, lymphoma-associated macrophages, and MUM-1 expression in follicular lymphoma treated before and after the introduction of monoclonal antibody therapy: a Southwest Oncology Group Study. Ann Oncol 21(6):1196-1202. https://doi.org/10.1093/ annonc/mdp460

82. Cheung KJ, Shah SP, Steidl C, Johnson N, Relander T, Telenius A et al (2009) Genome-wide profiling of follicular lymphoma by array comparative genomic hybridization reveals prognostically significant DNA copy number imbalances. Blood 113(1):137148. https://doi.org/10.1182/blood-2008-02-140616

83. Yunis JJ, Frizzera G, Oken MM, McKenna J, Theologides A, Arnesen M (1987) Multiple recurrent genomic defects in follicular lymphoma. A possible model for cancer. N Engl J Med 316(2): 79-84. https://doi.org/10.1056/NEJM198701083160204

84. Tilly H, Rossi A, Stamatoullas A, Lenormand B, Bigorgne C, Kunlin A et al (1994) Prognostic value of chromosomal abnormalities in follicular lymphoma. Blood 84(4):1043-1049

85. Eide MB, Liestol K, Lingjaerde OC, Hystad ME, Kresse SH, Meza-Zepeda L et al (2010) Genomic alterations reveal potential for higher grade transformation in follicular lymphoma and confirm parallel evolution of tumor cell clones. Blood 116(9):1489 1497. https://doi.org/10.1182/blood-2010-03-272278

86. Lossos IS, Levy R (2000) Higher-grade transformation of follicle center lymphoma is associated with somatic mutation of the $5^{\prime}$ noncoding regulatory region of the BCL-6 gene. Blood 96(2): 635-639

87. Matolcsy A, Casali P, Warnke RA, Knowles DM (1996) Morphologic transformation of follicular lymphoma is associated with somatic mutation of the translocated Bcl-2 gene. Blood 88(10):3937-3944

88. Davies AJ, Lee AM, Taylor C, Clear AJ, Goff LK, Iqbal S et al (2005) A limited role for TP53 mutation in the transformation of follicular lymphoma to diffuse large B-cell lymphoma. Leukemia 19(8):1459-1465. https://doi.org/10.1038/sj.leu.2403802

89. Sander CA, Yano T, Clark HM, Harris C, Longo DL, Jaffe ES et al (1993) p53 mutation is associated with progression in follicular lymphomas. Blood 82(7):1994-2004

90. Elenitoba-Johnson KS, Gascoyne RD, Lim MS, Chhanabai M, Jaffe ES, Raffeld M (1998) Homozygous deletions at chromosome 9p21 involving p16 and p15 are associated with histologic progression in follicle center lymphoma. Blood 91(12):46774685

91. Pastore A, Jurinovic V, Kridel R, Hoster E, Staiger AM, Szczepanowski $M$ et al (2015) Integration of gene mutations in risk prognostication for patients receiving first-line immunochemotherapy for follicular lymphoma: a retrospective analysis of a prospective clinical trial and validation in a population-based registry. Lancet Oncol 16(9):1111-1122. https://doi.org/10.1016/S1470-2045(15)00169-2

92. Bains P, Al Tourah A, Campbell BA, Pickles T, Gascoyne RD, Connors JM et al (2013) Incidence of transformation to aggressive lymphoma in limited-stage follicular lymphoma treated with radiotherapy. Ann Oncol 24(2):428-432. https://doi.org/10.1093/ annonc/mds 433

93. Gleeson M, Hawkes EA, Peckitt C, Wotherspoon A, Attygalle A, Sharma B et al (2017) Outcomes for transformed follicular 
lymphoma in the rituximab era: the Royal Marsden experience 2003-2013. Leuk Lymphoma 58(8):1805-1813. https://doi.org/ 10.1080/10428194.2016.1265114

94. Lerch K, Meyer AH, Stroux A, Hirt C, Keller U, Viardot A et al (2015) Impact of prior treatment on outcome of transformed follicular lymphoma and relapsed de novo diffuse large B cell lymphoma: a retrospective multicentre analysis. Ann Hematol 94(6): 981-988. https://doi.org/10.1007/s00277-015-2303-5

95. Williams CD, Harrison CN, Lister TA, Norton AJ, Blystad AK, Coiffier B et al (2001) High-dose therapy and autologous stem-cell support for chemosensitive transformed lowgrade follicular non-Hodgkin's lymphoma: a case-matched study from the European Bone Marrow Transplant Registry. J Clin Oncol 19(3):727-735. https://doi.org/10. 1200/JCO.2001.19.3.727

96. Villa D, Crump M, Panzarella T, Savage KJ, Toze CL, Stewart DA et al (2013) Autologous and allogeneic stem-cell transplantation for transformed follicular lymphoma: a report of the Canadian blood and marrow transplant group. J Clin Oncol 31(9):11641171. https://doi.org/10.1200/JCO.2012.44.0693

97. Doocey RT, Toze CL, Connors JM, Nevill TJ, Gascoyne RD, Barnett MJ et al (2005) Allogeneic haematopoietic stem-cell transplantation for relapsed and refractory aggressive histology nonHodgkin lymphoma. Br J Haematol 131(2):223-230. https://doi. org/10.1111/j.1365-2141.2005.05755.x

98. Ratanatharathorn V, Uberti J, Karanes C, Abella E, Lum LG, Momin F et al (1994) Prospective comparative trial of autologous versus allogeneic bone marrow transplantation in patients with non-Hodgkin's lymphoma. Blood 84(4):1050-1055

99. Reddy N, Greer JP, Goodman S, Engelhardt B, Oluwole O, Jagasia MH et al (2012) Long-term outcome after autologous or allogeneic stem cell transplantation in patients with recurrent follicular lymphoma. Bone Marrow Transplant 47(10):1318-1320. https://doi.org/10.1038/bmt.2012.10

100. Ramadan KM, Connors JM, Al-Tourah AJ, Song KW, Gascoyne $\mathrm{RD}$, Barnett MJ et al (2008) Allogeneic SCT for relapsed composite and transformed lymphoma using related and unrelated donors: long-term results. Bone Marrow Transplant 42(9):601-608. https://doi.org/10.1038/bmt.2008.220
101. Peyrade F, Jardin F, Thieblemont C, Thyss A, Emile JF, Castaigne $\mathrm{S}$ et al (2011) Attenuated immunochemotherapy regimen (RminiCHOP) in elderly patients older than 80 years with diffuse large B-cell lymphoma: a multicentre, single-arm, phase 2 trial. Lancet Oncol 12(5):460-468. https://doi.org/10.1016/S14702045(11)70069-9

102. Fields PA, Townsend W, Webb A, Counsell N, Pocock C, Smith P et al (2014) De novo treatment of diffuse large B-cell lymphoma with rituximab, cyclophosphamide, vincristine, gemcitabine, and prednisolone in patients with cardiac comorbidity: a United Kingdom National Cancer Research Institute trial. J Clin Oncol 32(4):282-287. https://doi.org/10.1200/JCO.2013.49.7586

103. Czuczman MS, Vose JM, Witzig TE, Zinzani PL, Buckstein R, Polikoff J et al (2011) The differential effect of lenalidomide monotherapy in patients with relapsed or refractory transformed non-Hodgkin lymphoma of distinct histological origin. $\mathrm{Br} \mathrm{J}$ Haematol 154(4):477-481. https://doi.org/10.1111/j.1365-2141. 2011.08781.x

104. Anderson MA, Huang D, Roberts A (2014) Targeting BCL2 for the treatment of lymphoid malignancies. Semin Hematol 51(3): 219-227. https://doi.org/10.1053/j.seminhematol.2014.05.008

105. Aalipour A, Advani RH (2013) Bruton tyrosine kinase inhibitors: a promising novel targeted treatment for B cell lymphomas. Br J Haematol 163(4):436-443. https://doi.org/10.1111/bjh.12573

106. Gopal AK, Kahl BS, de Vos S, Wagner-Johnston ND, Schuster SJ, Jurczak WJ et al (2014) PI3Kdelta inhibition by idelalisib in patients with relapsed indolent lymphoma. N Engl J Med 370(11): 1008-1018. https://doi.org/10.1056/NEJMoa1314583

107. Burger JA, Okkenhaug K (2014) Haematological cancer: idelalisib-targeting PI3Kdelta in patients with B-cell malignancies. Nat Rev Clin Oncol 11(4):184-186. https://doi.org/10. 1038/nrclinonc. 2014.42

108. Friedberg JW, Mahadevan D, Cebula E, Persky D, Lossos I, Agarwal AB et al (2014) Phase II study of alisertib, a selective Aurora A kinase inhibitor, in relapsed and refractory aggressive Band T-cell non-Hodgkin lymphomas. J Clin Oncol 32(1):44-50. https://doi.org/10.1200/JCO.2012.46.8793 